\title{
Neural Network Analysis in Forecasting the Malaysian GDP*
}

\author{
Nur Azura SANUSI ${ }^{1}$, Adzie Faraha MOOSIN², Suhal KUSAIRI ${ }^{3}$ \\ Received: September 01, 2020 Revised: October 26, 2020 Accepted: November 05, 2020
}

\begin{abstract}
The aim of this study is to develop basic artificial neural network models in forecasting the in-sample gross domestic product (GDP) of Malaysia. GDP is one of the main indicators in presenting the macro economic condition of a country as set by the world authority bodies such as the World Bank. Hence, this study uses an artificial neural network-based approach to make predictions concerning the economic growth of Malaysia. This method has been proposed due to its ability to overcome multicollinearity among variables, as well as the ability to cope with non-linear problems in Malaysia's growth data. The selected inputs and outputs are based on the previous literatures as well as the economic growth theory. Therefore, the selected inputs are exports, imports, private consumption, government expenditure, consumer price index (CPI), inflation rate, foreign direct investment (FDI) and money supply, which includes M1 and M2. Whilst, the output is real gross domestic product growth rate. The results of this study showed that the neural network method gives the smallest value of mean error which is 0.81 percent with a total difference of 0.70 percent. This implies that the neural network model is appropriate and is a relevant method in forecasting the economic growth of Malaysia.
\end{abstract}

Keywords: Economic Growth, Developed Nation, Forecasting, Neural Network, NARX Model

JEL Classification Code: O4, F63, C53, C45

\section{Introduction}

GDP is one of the measurements of economic growth for a country. Economic growth not only represents the economic development of a country; it also represents its technological advancement and international openness, as well as the demand for domestic goods and domestic demand for goods.

\footnotetext{
*Acknowledgements:

This project is funded by the Fundamental Research Grant Scheme of Ministry of Higher Education Malaysia (MOHE) (Vot number: FRGS 59234). The authors would like to thank MOHE and Universiti Malaysia Terengganu for supporting this research.

${ }^{1}$ First Author and Corresponding Author. Professor, Faculty of Business, Economics and Social Development, Universiti Malaysia Terengganu, Malaysia [Postal Address: 21030 Kuala Nerus, Terengganu, Malaysia] Email: nurazura@umt.edu.my

${ }^{2}$ Assistant Registrar, Faculty of Business, Economics and Social Development, Universiti Malaysia Terengganu, Malaysia.

Email: adziefaraha@gmail.com

${ }^{3}$ Associate Professor, Faculty of Business, Economics and Social Development, Universiti Malaysia Terengganu, Malaysia.

Email: suhal@umt.edu.my

(C) Copyright: The Author(s)

This is an Open Access article distributed under the terms of the Creative Commons Attribution Non-Commercial License (https://creativecommons.org/licenses/by-nc/4.0/) which permits unrestricted non-commercial use, distribution, and reproduction in any medium, provided the original work is properly cited.
}

In the case of Malaysia, according to the National Economic Model (NEM), the transition from a low-income country to a middle-income country is one of Malaysia's accomplishments over the past few decades, and one of the indicators is economic growth. Malaysia needs to achieve a minimum level of economic growth to meet the requirements set by international bodies.

However, Malaysia faces some difficulties in achieving its goals. This is because the outline in Vision 2020 has targeted Malaysia GDP growth at seven percent per year. Unfortunately, in reality, between the year 1991 and 2010, Malaysia's GDP grew only at 5.4 percent per year (Economic Planning Unit, 2010). The Asian financial crisis that began around the end of 1997 affected the GDP growth of Malaysia (Economic Planning Unit, 2001). As a result, there has been a 26 percent gap between real achievement and targeted GDP, as shown in Figure 1.

According to the National Economic Advisory Council (2011), Malaysia has achieved outstanding success for the past three decades using the previous policy and strategic growth model. However, the policies and strategies that have been implemented so far are no longer relevant and are unable to respond to changes in the current environment and condition of Malaysia. In other words, new policies and strategies need to be implemented in Malaysia in order to achieve the status of a developed nation, as outlined in Vision 2020. 


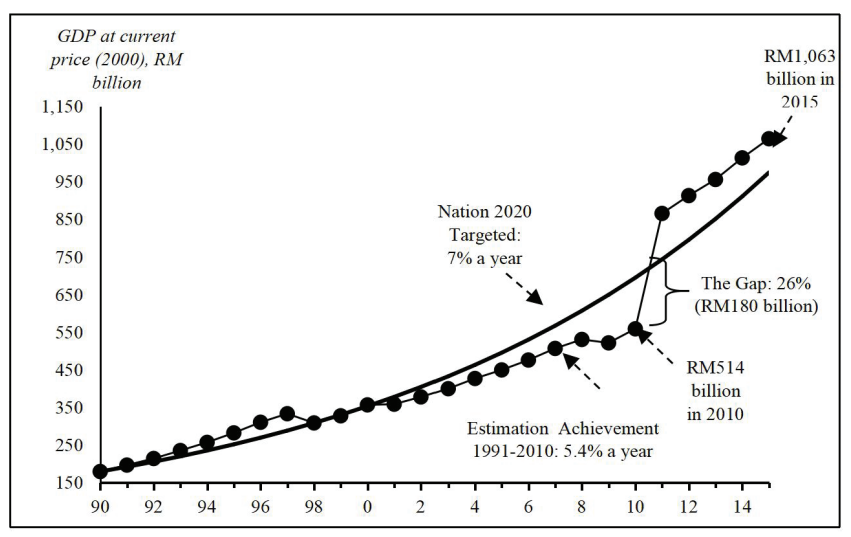

Source: Economic Planning Unit (2010)

Figure 1: GDP Growth 1991 to 2015

This situation can be explained in Figure 1. The GDP growth rates have improved from the First Malaysia Plan (2018) to the Sixth Malaysia Plan (2018). However, GDP growth decreased afterwards. The Ninth Malaysia Plan (2018) recorded the lowest GDP growth rate of only 4.5 percent. This is due to the economic crisis caused by the subprime mortgage crisis in the United States of America, which led to the global financial crisis. In 2015, the GDP growth rate was 5.6 percent. The slow GDP growth has kept Malaysia in the middle-income group and trapped in between developing countries that are growing more rapidly into the new global markets (Economic Planning Unit, 2011).

To evaluate this gap, an accurate technique is needed. The more accurate the estimation, the more it will minimize the error between actual achievement and expected achievement. The scenario in Figure 1 shows that gap between real achievement and targeted values is wider. Therefore, it is important to evaluate the gap between actual achievement and the targeted value in order to help the policymakers to readjust/realign the future targeting of values, especially for short-term targets.

Hence, this study attempts to use a neural network approach to forecast Malaysia's GDP growth with some other relevant variables. This method has been proposed due to its ability to overcome multicollinearity among the variables, as well as the ability to cope with non-linear problems in Malaysia's growth data.

Neural network computing applications are inspired by the brain and nervous system functioning. The structure of neural network processing consists of multiple layers, which are the input layer, the output layer and a few other layers between the input and the output layers, called the hidden layers. The processing elements are related through weights, which can be customized.

\section{Literature Review}

Neural networks have been widely used in various fields such as engineering, science, mathematics, medicine, business, finance, and so on. This is because the neural network is very efficient in solving non-linear functions such as business forecasting, medical, and patent recognition (Liliana \& Napitupulu, 2012). Most researchers have claimed that the ANN model is a powerful tool in forecasting (Zemouri, Gouriveau, \& Zerhouni, 2010; Menezes \& Barreto, 2008; Lam, 2004; Co \& Boosarawongse, 2007; Zhang, Hu, Patuwo, \& Indro, 1999; Kaastra \& Boyd, 1996; Celik \& Karatepe, 2007; Ismail \& Khamis, 2003).

Liliana and Napitupulu (2012) applied the neural network model to predict the GDP growth of Indonesia. The study used economic variables such as population growth, inflation, and exchange rate for the period from 1980 to 2009. In the study, they found that the neural network method has its own advantage in solving non-linear problems. This study reported that the results of their prediction were more accurate than those by the Indonesian government report.

The neural network method is more extensively applied in various fields as a forecasting tool. Zhang, Hu, Patuwo and Indro (1999) conducted firm bankruptcy prediction and classifications using samples from 220 firms from 1980 to 1991. This study used a few variables such as total assets of the firm, profit before tax and interest rates, value of equity, total debt, and total firm sales. They compared the neural network method with logistic equations, which is also known as the statistical method. The findings of the study found that the neural network method is better compared to logistics equations.

A study by Lam (2004) reviewed the effectiveness of the neural network method in predicting financial performance. His study looked at 16 financial statements from 1985 to 1995. The variables used in this study were the ratio of current assets to current liabilities, the ratio of net sales to assets, the ratio of net income to total sales, capital expenditures, and total dividends. The findings of this study support the utility of the neural network method in predicting the financial performance using a three hidden layer neural network model.

The neural network method was also used to forecast Thailand's rice exports. A study conducted by $\mathrm{Co}$ and Boosarawongse (2007) compared several statistical methods with the neural network model. In their study they used the Holt-Winters method and the Box-Jenkins method as their statistical methods. This study aimed to predict the total exports for each type of Thai rice such as white rice, glutinous rice, and jasmine rice. This study covering data from 1996 to 2004 showed that the performance of neural network is relatively better as it gives the lowest value of Mean Square Error (MSE). Additionally, it also proved that the Holt-Winters method performed better than the Box-Jenkins method. 
According to Kaastra and Boyd (1996), the neural network method is a very effective method for forecasting, classification and pattern recognition. It is a universal method because it can analyze and solve non-linear functions. However, according to Tkacz's (2001) study of forecasting Canadian GDP growth, he found that the neural network did not perform well in forecasting Canadian GDP and cannot prove that the neural network model is better than the classical model. This study covered quarterly data from 1968 to 1999 with respect to some variables such as interest rates, consumer price index, and inflation rate. Money supply includes M1 and M2 and real GDP. The research concluded that the neural network method is relevant in predicting GDP growth for only a short period of time.

Another study by Celik and Karatepe (2007) predicted a banking crisis using a neural network model. Based on their study, neural networks have proven an effective way to evaluate and forecast banking crises. However, they also believed that traditional methods still had their own advantages in forecasting.

In Malaysia, the neural network method has been used to predict the price of palm oil. Ismail and Khamis (2003) forecast palm oil prices for Peninsular Malaysia and also Sabah and Sarawak. The variables used in the study were the price of palm oil, coconut oil, palm kernel oil, and palm seed oil from 1983 until 2000. This study used back propagation neural network analysis (BPNN). The results of this study found that the neural network analysis can be used as an alternative to analyze data involving multicollinearity problems.

The objective of this study is to develop basic models to forecast economic performance. Specifically, the objectives of this study are (i) to establish the basic model of economic growth based on the theory of Artificial Intelligence (AI), (ii) to identify the processing elements that involve input stimulus, output stimulus, and hidden stimulus, and (iii) to forecast economic growth in Malaysia using Artificial Neural Network (ANN).

\section{Research Methods}

The data used in this study covers the period from 1970 to 2015. The research derives its data from the World Bank (2012) and Department of Statistic Malaysia (DOSM). ANN is a non-parametric approach based on an intelligence system. Therefore, the sample size is adequate to run the analysis due to the intelligence of ANN. In the case of NARX, for NARX models that used a sample data with less than 60 observations, the reported normalized mean square error (NMSE) values are approximately the same for the NARX, time delay neural network, and Elman architectures (Menezes \& Barreto, 2008).

\subsection{Neural Network Model Analysis}

A neural network analysis has been carried out using Neural Network Analysis with Autoregressive Nonlinear External (exogenous) input (NARX). In this study the data is divided into the input and output levels. For the output level, only one variable used (real GDP growth rate), and for the input level, eight variables are used, which are:

1. The total of Exports Malaysia (RM Million) (EXP)

2. The total of Imports Malaysia (RM Million) (IMP)

3. The total Private Consumption of Malaysia (RM Million) (PC)

4. The total Government Expenditure of Malaysia (RM Million) (GE)

5. The total of the Consumer Price Index $($ CPI $)(2000=100)$ (CPI)

6. The Inflation Rate (\%)(INF)

7. The Foreign Direct Investment (FDI) (Share of GDP) (FDI)

8. The Money Supply, which includes M1 and M2 (RM Million) (MS)

All the selected variables are based on the determinants of economic growth studies by Tariq, Khan and Rahman (2020), Dinh (2020) and Nguyen and Pham (2020). Before a prediction is developed, there are a few steps that should be taken in order to choose the best and accurate model for forecasting. This procedure is recommended by Kaastra and Boyd (1996) for financial forecasting and economic time series. The procedure is summarized as:

1. Selection of Variables

2. Data Collection

3. Data Processing

4. Training, Testing and Verification (Training, Testing, and Validation Tests)

5. Neural Network Paradigm

(i) The number of hidden levels

(ii) The number of hidden neurons

(iii) The number of output neurons

(iv) The transfer function

6. Selection Criteria

7. Test Neural Network

(i) Number of tests

(ii) Learning rate and momentum

8. Implementation

The selection of an appropriate model is one of the most important steps in ensuring accuracy when forecasting the GDP growth of Malaysia. The model will be chosen based on the smallest value of Mean Square Error (MSE) in NARX. The neural network model with the smallest MSE value will be considered to be the best neural network model. 
Data used in the neural network analysis need to be transformed into normalized data using equation 1 . The data should be normalized to the range of $0-1$ to ensure consistency.

$$
x_{i=\frac{x_{i-x_{\min }}}{x_{\operatorname{maks}-x_{\min }}}}
$$

Where $\chi \mathrm{i}$ is the observation, $\chi \mathrm{min}$ is lowest for each order observed variables, and $\chi \max$ is the highest observed for each variable. $\mathrm{i}$ is represented by EXP, IMP, PC, GE, CPI, INF, FDI and MS, respectively.

The standard NARX network is a two-layer feed forward network with a sigmoid transfer function in the hidden layer and a linear transfer function in the output layer. This network also uses tapped delay lines (d) or lag to store previous values of the input $\mathrm{x}(\mathrm{t})$ and output $\mathrm{y}(\mathrm{t})$ sequences. In this study an output or $\mathrm{y}(\mathrm{t})$ is the gdpg. While the remaining variables are the input or $\mathrm{x}(\mathrm{t})$.

$X(t)$ and $y(t)$ are two inputs for the series-parallel network. The $y(t)$ sequence is considered a feedback signal that also acts as input and output (target). In this study the GDPG refers to the GDP growth rate of Malaysia. The model can be shown in equation 2 as follows:

$$
\begin{aligned}
\mathrm{GDPG}(\mathrm{t})= & \mathrm{F}(\mathrm{GDPG}(\mathrm{t}-1)) \ldots, \mathrm{GDPG}\left(\mathrm{t}-\mathrm{n}_{\mathrm{GDPG}}\right), \operatorname{EXP}(\mathrm{t}-1) \ldots, \\
& \operatorname{EXP}\left(\mathrm{t}-\mathrm{n}_{\mathrm{EXP}}\right), \operatorname{IMP}(\mathrm{t}-1) \ldots ., \\
& \operatorname{IMP}\left(\mathrm{t}-\mathrm{n}_{\mathrm{IMP}}\right), \operatorname{PC}(\mathrm{t}-1) \ldots, \operatorname{PC}\left(\mathrm{t}-\mathrm{n}_{\mathrm{PC}}\right), \mathrm{GE}(\mathrm{t}-1) \ldots, \\
& \operatorname{GE}\left(\mathrm{t}-\mathrm{n}_{\mathrm{GE}}\right), \operatorname{CPI}(\mathrm{t}-1) \ldots, \\
& \operatorname{CPI}\left(\mathrm{t}-\mathrm{n}_{\mathrm{CPI}}\right), \operatorname{INF}(\mathrm{t}-1) \ldots, \operatorname{INF}\left(\mathrm{t}-\mathrm{n}_{\mathrm{INF}}\right), \operatorname{FDI}(\mathrm{t}-1) \ldots, \\
& \operatorname{FDI}\left(\mathrm{t}-\mathrm{n}_{\mathrm{FD}}\right), \\
& \operatorname{MS}(\mathrm{t}-1) \ldots, \operatorname{MS}\left(\mathrm{t}-\mathrm{n}_{\mathrm{MS}}\right)+\mathrm{e}(\mathrm{t})
\end{aligned}
$$

Where the destination of the input and output as described in page 8, GDPG is the output (target) of the NARX network. $n_{\text {GDPG }}, n_{\text {EXP }}, n_{\mathrm{IMP}}, n_{\mathrm{PC}}, \mathrm{n}_{\mathrm{GE}}, \mathrm{n}_{\mathrm{CPI}}, \mathrm{n}_{\mathrm{INF}}, \mathrm{n}_{\mathrm{FDI}}$ and $\mathrm{n}_{\mathrm{MS}}$ are the tapped delay lines that store the previous values of $n_{\text {GDPG }}$, EXP, IMP, PC, GE, CPI, INF, FDI, MS, and GDPG sequences.

The diagram of the NARX network is shown in Figure 2. The transfer function in the hidden layer is the sigmoid transfer function, while the linear transfer function is in the output layer. $X(t)$ is the input or independent variables of the NARX network, and $y(t)$ is the input and also the output (target) of the model.

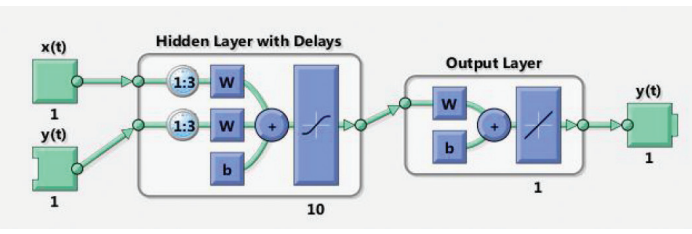

Figure 2: The snapshot of NARX network

\subsection{The Selection of the NARX Model}

The selection of the best model is vital to ensure that the model is able to produce accurate forecasts. In the process of selecting the best model, the number of hidden neurons and lag were modified in order to achieve the smallest MSE. The model with the smallest MSE value will be selected as the best model and will be used to forecast the GDP growth of Malaysia.

The analysis was performed by randomly dividing 46 target time steps into three parts for the purposes of training, validation, and testing. The three parts are also known as three kinds of target time steps. The training is presented to the network during the training period, and the network is adjusted according to its error. The validation is used to measure network generalization and to halt training when generalization stops improving, while testing has no effect on training and provides an independent measure of network performance during and after training. In this study, the three target time steps are:

1. Training: $70 \%$ (32 target time steps)

2. Validation: $15 \%$ (7 target time steps)

3. Testing: $15 \%$ (7 time steps)

We conduct NARX with a number of hidden neurons and tapped delay lines (d). The process of selecting hidden neurons is more of an art than a mathematical method. When the number of hidden neurons is small, the correlation of the output and input cannot be studied well, and the errors will increase. On the other hand, when the number of hidden neurons is adequate, and even if irrelevant noise interferes with the study of the correlation of both output and input, the error will grow accordingly. There are some methods to obtain the number of hidden neurons. However, there is no general solution to this problem (Roldao \& Cancela, 2008).

Baily and Thompson (1990) suggest that the number of hidden layer neuron is a three-layer neural network should be $75 \%$ of the number of input neurons, hence this study applied different number of hidden neurons, chosen randomly, with 10,30 and 50 neurons in the hidden layer as to describe the best structure of neural network.

\section{Results and Discussion}

This section will discuss the findings of this study, which includes the best NARX model selection and the prediction of Malaysia GDP growth using NARX.

The NARX model was analyzed by considering one and two number of lags. After several trials, the method of the NARX model gave the smallest MSE value on the network which has one number of tapped lines delay (d) with 50 
hidden neurons, as shown in Table 1. Therefore, this model will be used in GDP growth prediction in Malaysia.

This study will use a NARX model with 50 hidden neurons and one tapped lines delay (d) to predict the GDP growth of Malaysia. Iterations of 128 epochs have been recorded during the training. The result of the predicted values will be compared to the actual values of GDP growth to test the utility of the proposed method.

Table 2 shows the comparison between the forecasted NARX value and the government estimation of real GDP growth rate for an average of five years. The table shows that the error given by the neural network model is smaller than the estimation made by the Malaysian government. The mean error of the NARX prediction is 0.81 percent, which is smaller than the mean error of the government's estimation of 1.51 percent. Error is calculated using the absolute value without taking the positive and negative values into account. Thus, the neural network method is a relevant method to be used by the government to forecast GDP growth in Malaysia.

\section{Conclusion}

By comparing neural network forecasting method and the government's estimation, it has shown that the neural network method gives the smallest value of mean error which is only 0.81 percent, while the mean error estimated by the government is 1.51 percent. This gives a total difference of 0.70 percent. Hence it can be concluded that the NARX network has a better ability in terms of accuracy to forecast GDP growth in Malaysia. Even though the neural network forecasting is smaller compare to the government estimation at the end of Ninth Malaysia Plan (9MP) and Tenth Malaysia Plan (10MP), Malaysia economic growth rise up to 5.6 percent during the slowdown of global economic trend compared to the Asia Pacific countries (3.8 percent).

Table 1: The Selection of NARX Model

\begin{tabular}{|l|c|c|c|c|}
\hline \multirow{3}{*}{ Tapped lines delay,d } & \multirow{2}{*}{ No. of Hidden Neuron } & \multicolumn{3}{|c|}{ MSE of } \\
\cline { 2 - 5 } & & Training & Validation & Testing \\
\hline \multirow{3}{*}{1} & 10 & 0.1743 & 0.1399 & 0.4518 \\
\cline { 2 - 5 } & 30 & 0.1462 & 0.4803 & 0.1757 \\
\cline { 2 - 5 } & 50 & 0.1110 & 0.1073 & 0.1303 \\
\hline \multirow{3}{*}{2} & 10 & 0.1776 & 0.3165 & 0.3367 \\
\cline { 2 - 5 } & 30 & 0.6836 & 0.1404 & 0.1246 \\
\hline
\end{tabular}

Table 2: The Comparison Prediction Results

\begin{tabular}{|c|c|c|c|c|c|}
\hline Period & $\begin{array}{c}\text { Real GDP Growth } \\
\text { Rate }\end{array}$ & $\begin{array}{l}\text { Neural Network } \\
\text { Forecasting }\end{array}$ & $\begin{array}{l}\text { Government } \\
\text { Estimates* }\end{array}$ & $\begin{array}{c}\text { Neural Network } \\
\text { Error }\end{array}$ & $\begin{array}{c}\text { Government } \\
\text { Estimates Error }\end{array}$ \\
\hline & $(\%)$ & $(\%)$ & (\%) & (\%) & $(\%)$ \\
\hline 1966-1970 & 5.4 & - & 6.00 & - & - \\
\hline $1971-1975$ & 6.00 & 7.40 & 7.00 & $|1.4|$ & $|1.0|$ \\
\hline 1976-1980 & 8.00 & 7.60 & 8.50 & $|0.4|$ & $|0.5|$ \\
\hline 1981-1985 & 5.20 & 4.10 & 7.60 & $|1.1|$ & $|2.4|$ \\
\hline $1986-1990$ & 5.90 & 5.80 & 5.00 & $|0.1|$ & $|0.9|$ \\
\hline 1991-1995 & 8.70 & 8.50 & 7.50 & $|0.2|$ & $|1.2|$ \\
\hline $1996-2000$ & 5.00 & 6.70 & 8.00 & $|1.7|$ & $|3.0|$ \\
\hline 2001-2005 & 4.80 & 6.00 & 7.50 & $|1.2|$ & $|2.7|$ \\
\hline $2006-2010$ & 4.50 & 5.00 & 6.00 & $|0.5|$ & $|1.5|$ \\
\hline $2011-2015$ & 5.60 & 4.60 & 6.00 & $|1.0|$ & $|0.4|$ \\
\hline Mean Error & & & & 0.81 & 1.51 \\
\hline
\end{tabular}

Note: * indicates the government estimation from the First Malaysia Plan until Tenth Malaysia Plan. 


\section{References}

Baily, D., \& Thompson, D. M. (1990). Developing neural network applications. AI Expert, 12, 33-41.

Celik, A. E., \& Karatepe, Y. (2007). Evaluating and forecasting banking crises through neural network models: An application for Turkish banking sector. Expert Systems with Applications, 33, 809-815.

Co, C. H., \& Boosarawongse, R. (2007). Forecasting Thailand's rice export: Statistical techniques vs. artificial neural networks. Computers \& Industrial Engineering, 53, 610-627.

Dinh, D. V. (2020). Impulse response of inflation to economic growth dynamics: VAR model analysis. Journal of Asian Finance, Economics and Business, 7(9), 219-228. https://doi. org/10.13106/jafeb.2020.vol7.no9.219

Economic Planning Unit (EPU). (2001). Outlined Perspective Plan III. Kuala Lumpur: Malaysia's National Printer.

Economic Planning Unit (EPU). (2010). First Guideline of $10^{\text {th }}$ Malaysia Plan. Retrieved January 24, 2018, from https://www. epu.gov.my/en/resources/guidelines-and-procedures/firstguideline-10th-malaysia-plan

Economic Planning Unit (EPU). (2011). 10 ${ }^{\text {th }}$ Malaysia Plan 20112015. Retrieved January 24, 2018, from https://www.pmo.gov. my/dokumenattached/RMK/RMK10_E.pdf

First Malaysia Plan. Prime Minister Office, (2018). Retrieved on January 24, 2018, from http://www.pmo.gov.my/ dokumenattached/RMK/RMK1.pdf

Ismail, Z., \& Khamis. A. (2003). Neural network in the prediction of palm oil prices. Journal of Technology, 39, 17-28.

Kaastra, I., \& Boyd, M. (1996). Designing a neural network for forecasting financial and economic time series. Neurocomputing, 10, 215-236.

Lam, M. (2004). Neural network techniques for financial performance prediction: Integrating fundamental and technical analysis. Decision Support Systems, 37, 567-581.

Liliana, \& Napitupulu, T. A. (2012). Artificial neural network application in gross domestic product forecasting an Indonesia case. Journal of Theoretical and Applied Information Technology, 45(2), 410-415.
Menezes Jr, J. M. P., \& Barreto, G. A. (2008). Long-term time series prediction with the NARX network: An empirical evaluation. Neurocomputing, 71(16-18), October, 3335-3343.

National Economic Advisory Council. (2011). An Executive Summary of New Economic Model of Malaysia. Kuala Lumpur: Malaysia's National Printer.

Nguyen, L. P., \& Pham, V. H. T. (2020). Trade of ICT products, government, and economic growth: Evidence from East AsiaPacific region. Journal of Asian Finance, Economics and Business, 7(8), 175-183. https://doi.org/10.13106/jafeb.2020.vol7.no8.175

Ninth Malaysia Plan. Prime Minister Office, (2018). Retrieved January 24, 2018, from http://www.pmo.gov.my/dokumen attached/RMK/RM9_E.pdf

Roldao Cancela, A. M. (2008). Comparative study of artificial neural network and Box-Jenkins ARIMA for stock prices indexes. Retrieved February 1, 2018, from https://repositorio. iscteiul.pt/bitstream/10071/1472/1/comparative $\% 20$ study $\% 20$ of $\% 20$ artificial $\% 20$ neural $\% 20$ network $\% 20$ and $\% 20$ boxjenkins $\% 20$ arima $\% 20$ for $\% 20$ stock $\% 20$ price $\% 20$ indexes.pdf

Sixth Malaysia Plan. Prime Minister Office, (2018). Retrieved January 24, 2018, from http://www.pmo.gov.my/dokumenattached/RMK/RM6.pdf

Tariq, R., Khan, M. A., \& Rahman, A. (2020). How does financial development impact economic growth in Pakistan?: New evidence from threshold model. Journal of Asian Finance, Economics and Business, 7(8), 161-173. https://doi. org/10.13106/jafeb.2020.vol7.no8.161

Tkacz, G. (2001). Neural network foreasting of Canadian GDP growth. International Journal of Forecasting, 17, 57-69.

World Bank. (2012). Retrieved February 15, 2012, from http://data. worldbank.org/indicator

Zemouri, R., Gouriveau, R., \& Zerhouni, N. (2010). Defining and applying prediction performance metrics on a recurrent NARX time series model. Neurocomputing, 73(13-15), August, 2506-2521.

Zhang, G., Hu, Y. M., Patuwo, E. D., \& Indro, C. D. (1999). Artificial neural network in bankcruptcy prediction: General framework and cross-validation analysis. European Journal of Operational Research, 116, 16-32. 